\title{
Narrativas de educadores da socioeducação: representações sociais sobre adolescência na tessitura do trabalho socioeducativo
} Narratives of socio-education educators: social representations about adolescence in the context of socio-education work Narraciones de los educadores socioeducativos: representaciones sociales sobre la adolescencia en la producción del trabajo socioeducativo

\author{
ANA MARIA EYNG
}

AUDA RAMOS

\section{Resumo}

No texto colocamos sob interpretação as representações sociais de educadores da socioeducação sobre a adolescência. A abordagem transversal do objeto se dá na análise da rede de significados, que configuram as representações sociais de um grupo multiprofissional de educadores, os quais enunciam suas narrativas sobre um objeto e num contexto compartilhado. $O$ estudo das representações tem como aporte as contribuições de Moscovici (1961) e o aplicado nos estudos de Alves-Mazzotti (2015), Passeggi (2011), Ribeiro, Carvalho e Antunes-Rocha (2017), Sousa et al. (2014), Teibe e Andrade (2017). As narrativas em discussão advêm de estudo de campo, que abrangeu observação das dinâmicas de interação entre sujeitos no contexto das práticas socioeducativas e entrevistas individuais com a escuta de 17 educadores que compõem a equipe multiprofissional. Das narrativas dos educadores colocamos em destaque as significações sobre a

a Pontifícia Universidade Católica do Paraná (PUCPR), Curitiba, PR, Brasil. Doutora em Educação, e-mail: eyng.anamaria@gmail.com

b Pontifícia Universidade Católica do Paraná (PUCPR), Curitiba, PR, Brasil. Mestra em Filosofia, e-mail: audaramos@gmail.com 
adolescência e os adolescentes em cumprimento de medidas socioeducativas em meio aberto. As representações sociais extraídas das narrativas dos educadores estão ancoradas em duas direções em contradição que constituem as redes de significados acerca dos adolescentes. As representações sociais sobre a adolescência, nas quais ainda persistem narrativas da situação irregular, ampliam sobremaneira as demandas das práticas socioeducativas que, além do trabalho multidisciplinar, desafiam a desconstrução de tais referências na perspectiva da garantia dos direitos da infância.

Palavras-chave: Direitos da Infância. Adolescência. Pobreza Infantil. Socioeducação.

\begin{abstract}
In the text, we put the social representations of socio-educational educators on adolescence under interpretation. The transversal approach of the object, occurs in the analysis of the network of meanings that configure the social representations of a multiprofessional group of educators who enunciate their narratives about an object and in a shared context. The study of representations is based on the contributions of Moscovici (1961) and applied in the studies of Alves-Mazzotti (2015), Passeggi (2011), Ribeiro; Carvalho; Antunes-Rocha (2017), Sousa et al. (2014), Teibe and Andrade (2017). The narratives under discussion come from a field study, which included observation of the dynamics of interaction between subjects in the context of socio-educational practices and individual interviews with the listening of 17 educators who make up the multiprofessional team. From the educators' narratives, we highlight the meanings about adolescence and adolescents in compliance with socioeducational measures in an open environment. The social representations extracted from the educators' narratives are anchored in two contradictory directions that constitute the networks of meanings about adolescents. The social representations about adolescence, in which narratives of the irregular situation still persist, greatly expand the demands of socioeducational practices, which, in addition to multidisciplinary work, challenge the deconstruction of such references from the perspective of guaranteeing the rights of children.
\end{abstract}

Keywords: Children's Rights. Adolescence. Child poverty. Socio-education.

\title{
Resumen
}

En el texto, interpretamos las representaciones sociales de los educadores socioeducativos sobre la adolescencia. El enfoque transversal del objeto ocurre en el análisis de la red de significados, que configuran las representaciones sociales de un grupo multiprofesional de educadores, que enuncian sus narraciones sobre un objeto y en un contexto compartido. El estudio de las representaciones se basa en las contribuciones de Moscovici (1961) y se aplica en los estudios de Alves-Mazzotti (2015), Passeggi (2011), Ribeiro; Carvalho; Antunes-Rocha (2017), Sousa et al. (2014), Teibe y Andrade (2017). Las narraciones en discusión provienen de un estudio de campo, que incluyó la observación de la dinámica de interacción entre los sujetos en el contexto de prácticas socioeducativas y entrevistas individuales con la escucha de 17 educadores que conforman el equipo multiprofesional. De las narraciones de los educadores, destacamos los significados sobre la adolescencia y los adolescentes en cumplimiento de las medidas socioeducativas en un entorno abierto. Las representaciones sociales extraídas de las narrativas de los educadores están ancladas en dos direcciones contradictorias que constituyen las redes de 
significados sobre los adolescentes. Las representaciones sociales sobre la adolescencia, en las que persisten las narrativas de la situación irregular, amplían enormemente las demandas de las prácticas socioeducativas que, además del trabajo multidisciplinario, desafían la deconstrucción de tales referencias desde la perspectiva de garantizar los derechos del niño.

Palabras clave: Derechos del niño. Adolescencia. Pobreza infantil. Socioeducación.

\section{Introdução}

Em foco, as representações sociais de educadores que atuam na socioeducação sobre os sujeitos das medidas socioeducativas. A escuta das narrativas de uma equipe multiprofissional de socioeducadores, sobre a adolescência e sobre as intencionalidades e ações construídas e desenvolvidas em conjunto, permite delinear um mapa das representações que configuram o trabalho socioeducativo. Os adolescentes destinatários da socioeducação, em grande parte, vivem nas margens da exclusão e das desigualdades, sob a égide da pobreza infantil.

Nesses contextos, nos quais situamos a infância em situação humanitária, o conjunto de direitos da infância está sob risco, ou é frágil na garantia, ou é completamente ignorado. Assim, nos questionamos a respeito de quais representações sobre adolescência tecem a rede de significações que permeiam o trabalho socioeducativo. A questão que problematiza o mapeamento das representações sociais de socioeducadores permite compreender as redes de significações sobre adolescência que permeiam o trabalho com adolescentes no contexto da pobreza infantil, segundo

profissionais que trabalham na socioeducação. O estudo de campo abrangeu observação das dinâmicas de interação entre sujeitos, no contexto das práticas socioeducativas e em entrevistas individuais com a escuta de 17 educadores que compõem uma equipe multiprofissional. A formação e experiência dos profissionais nas áreas de psicologia, direito, sociologia, história e licenciaturas contemplam conhecimentos para suprir as demandas do trabalho considerando as necessidades intersetoriais da intervenção e apoio aos adolescentes em processos socioeducativos. A fundação na qual se desenvolve o trabalho de atendimento socioeducativo tem como missão "a prevenção do delito e a promoção da reintegração social daqueles que passam 
por conflitos penais; fortalecendo as capacidades de pessoas, famílias e comunidades, incidindo de maneira positiva nos processos de inclusão social" (CASTELLANOS GARCIA, 2012, p. 5).

Nas entrevistas individuais, os educadores apresentaram suas narrativas sobre os sujeitos, dinâmica e atuação no programa. Das narrativas dos educadores, colocamos em destaque as significações sobre a adolescência e os adolescentes em cumprimento de medidas socioeducativas em meio aberto.

\section{O aporte das representações sociais no delineamento metodológico}

A teoria das representações sociais - RS, sistematizada por Moscovici (1961, 1993) e as contribuições do estudos de Alves-Mazzotti (2015), Passeggi (2011), Ribeiro, Carvalho e Antunes-Rocha (2017), Sousa et al. (2014), Teibe e Andrade (2017), considera a ciência e a cultura como produções sociais; logo, essas se tornam elementos constitutivos das representações sociais ao criar "[...] pautas de aceitabilidade para a produção dos que com ela convivem e trabalham, pautas que regulam a comunicação entre si” (SOUSA et al., 2014, p. 148). As representações sociais constituem as narrativas da comunicação num determinado campo, contexto e grupos sociais, sendo, que a "[...] narrativa manifesta-se como possibilidade de partilha e compreensão do sentido da vida e da história nas práticas sociais [...]" (BRAGANÇA; LIMA, 2016, p. 293).

“As Representações Sociais têm sido utilizadas nas últimas décadas como um aporte teórico capaz de promover a análise entre diferentes tipos de informações em uma perspectiva dinâmica" (RIBEIRO; CARVALHO; ANTUNES-ROCHA, 2017, p. 345). Neste estudo, colocamos sob análise as informações advindas das narrativas dos profissionais da socioeducação participantes da investigação, buscando delinear as representações que movem e se movem no contexto da socioeducação. Referendamo- 
nos em Teibe e Andrade (2017), que elucidam três aspectos da relação entre representações sociais e intervenção:

1. a prática social depende da interpretação que os sujeitos sociais, indivíduos ou grupos fazem da sua realidade; 2. as representações sociais, compreendidas como filtro referencial de leitura do mundo, guia de ação e sistema de orientação de condutas e das comunicações, são formas de saber sobre a realidade na mesma medida que são formas de atuação sobre ela; 3. a atuação assume o status de intervenção [...] (TEIBE; ANDRADE, 2017, p. 89).

A análise da relação entre as representações e a intervenção nos programas de socioeducação requer a identificação das narrativas compartilhadas no espaço da intervenção, ou, segundo Teibe e Andrade (2017, p. 89), “"...] no espaço de vida ou de ação particular dos sujeitos envolvidos [...]". Essa identificação permite "[...] destacar as representações sociais que obstruem ou facilitam [...]" a construção da missão coletiva em prol dos adolescentes em cumprimento de medidas socioeducativas.

As autoras assinalam ainda que as representações sociais podem ser ressignificadas, pois por “[...] meio dos projetos de intervenção é possível criar condições favoráveis para a produção de novas representações dos objetos com os quais os sujeitos enfrentam, da realidade de seu mundo de vida, do seu envolvimento nela" (TEIBE; ANDRADE, 2017, p. 89).

A metodologia na perspectiva das representações sociais se orienta na abordagem interdisciplinar do objeto, para assim, "[...] melhor acercar-se ao seu objeto, facilita uma aproximação a outras formas de pesquisar: a observação participante, a etnografia, a pesquisa documental, entre outras" (SOUSA et al., 2014, p. 149).

A abordagem transversal do objeto se dá na análise das representações sociais de um grupo multiprofissional de educadores, que enunciam suas narrativas sobre um objeto e num contexto compartilhado. "Temos então, uma abertura em, pelo menos, dois sentidos. Um em direção a outros conhecimentos, à troca com outras disciplinas: outro, em direção a outras injunções do conhecer - a pesquisa como prática social" (SOUSA et al., 2014, p. 150). A troca com as diferentes disciplinas, o diálogo dos diferentes sujeitos permitem a ampliação do conhecimento sobre o objeto e de novas 
possibilidades de interação e inclusão nas práticas sociais em diálogo com os sujeitos e suas concepções sobre os objetos em diferentes contextualizações.

O método, como o dado, não existe de forma autônoma. Ele existe vinculado à concepção do objeto e da forma de conhecê-lo. Isto tem a ver com uma forma de encarar a construção do saber e o lugar do ser humano nesta construção, mesmo que eles não sejam sempre totalmente explicitados (SOUSA et al., 2014, p. 151).

A análise da dinâmica das narrativas nas redes de significações que veiculam as representações sociais pode resultar na "[...] desconstrução de crenças científicas e culturais para estabelecer uma nova visão do seu objeto de estudo [...]" (SOUSA et al., 2014, p. 151).

Esta visão dinâmica da produção investigativa é congruente com a visão dinâmica das representações sociais como característica das sociedades atuais, em constante movimento: os dados são matéria viva que continua pulsando e podem reviver sob uma outra interpretação, do próprio autor ou de outros (SOUSA et al., 2014, p.157).

Nessa direção, o aporte teórico das representações sociais, alinhado à perspectiva dos estudos culturais, potencializa as possibilidades de desconstrução das bipolaridades, próprias do pensamento moderno e das narrativas hegemônicas e monoculturais.

O olhar do pesquisador evolui, e ao voltar sobre o material, enxerga-o com novas nuances, comprovando que ele não se imobilizou sob a primeira aproximação, mas continua à espera de outras angulações (SOUSA et al., 2014, p. 157).

Portanto, há que se considerar a multiplicidade e dinamicidade dos objetos, contextos e sujeitos em movimento. "Tanto as representações quanto as interpretações estão em movimento; este movimento ocorre no cruzamento das comunicações e interações humanas. A ciência então se encontra com a arte: seu trabalho também é obra aberta" (SOUSA et al., 2014, p. 157). Assim, promove-se a necessária transição paradigmática das representações sociais sobre crianças e adolescentes em contextos demarcados pela pobreza infantil. 


\section{Estereótipos ancorados nas representações sobre a infância}

As representações sociais sobre crianças e adolescentes em contextos de pobreza infantil enunciam preconceitos e estereótipos que "[...] guiam nossa ação no mundo e que foram construídos na interação com tradições herdadas e reconstituídas, povoam nossa existência de dilemas, de sentimentos de inadequação e/ou de adequação aos ambientes sociais e criam zonas de conforto e/ou de desconforto" (PASSEGGI, 2011, p. 149).

Essa perspectiva de análise se referenda nos estudos de Sarmento (2010) que chama atenção para a ontologização da pobreza.

A pobreza como categoria ontológica atua como desqualificante moral e social, que configura o estigma da pobreza, passando a naturalizá-la, tomando-a como parte da essência do ser que está em situação de pobreza. Desvincula, portanto, a pobreza das condições estruturais que a produzem e mantém os sujeitos em estado de pobreza e, por consequência, na desigualdade. Há que se distinguir estado e essência - o estar pobre, situação gerada pelas condições estruturais que levam às privações, e o ser pobre (EYNG, 2019, p. 50).

Nossos estudos sobre a infância em contextos de pobreza permitem constatar a internalização de tais estereótipos pelas crianças e adolescentes que as adotam nas representações sobre si. Os "[...] significados construídos historicamente e instituídos socialmente podem influenciar o processo de significação da criança por meio da sua interação com os sujeitos e artefatos culturais presentes [...]" (TEIBE; ANDRADE, 2017, p. 88) nos cotidianos das crianças e adolescentes.

Os estudos sobre a pobreza infantil se referendam em duas perspectivas, sendo a primeira a abordagem unidimensional, que aborda a pobreza considerando a privação econômica, e a segunda, a abordagem multidimensional que aborda a pobreza na perspectiva da privação e fragilização do conjunto de direitos da infância. Assim, a pobreza infantil, na perspectiva multidimensional, representa a falta de garantia dos direitos de provisão, proteção e participação das crianças e adolescentes (FERNANDES, 2009). Essa abordagem inclui a privação econômica, mas considera 
que, além do nível de renda, um conjunto de outros recursos precisam ser garantidos para assegurar as condições de bem-estar de crianças e adolescentes (BASTOS et. al., 2008; SARMENTO, 2010; BASTOS et al., 2011; BASTOS; VEIGA, 2016; UNICEF, 2016).

Os adolescentes em contextos de pobreza infantil se situam às margens da garantia de direitos. Uma grande parcela desses adolescentes tem, aliados aos direitos de provisão e aos direitos de proteção, também seus direitos de participação fragilizados e/ou violados. Essa configuração os situa na perspectiva multidimensional da pobreza infantil.

\section{Narrativas sobre adolescência e os adolescentes da socioeducação}

Parte das narrativas sobre adolescência e sobre os adolescentes em conflito com a lei que constituem as representações sociais veiculam significados não condizentes com o paradigma do sujeito de direitos. No cenário de tais narrativas estão os indícios e desafios da necessária mudança de perspectiva nas narrativas sobre a adolescência e os adolescentes, em especial sobre os adolescentes sujeitos de atos infracionais.

Essa perspectiva alerta para uma transição paradigmática em curso, inaugurada pela Convenção dos direitos da criança - CDC (ONU, 1989, mas ainda bastante incipiente para grande parcela das crianças e adolescentes. A CDC concebe crianças e adolescentes como sujeitos de direitos e passa a requerer:

[...] a nível mundial, e sobretudo na América Latina, um novo modelo de resposta frente às condutas delitivas de pessoas menores de 18 anos de idade. Este se baseia na necessidade de construir uma legalidade que torne possível o pleno exercício de seus direitos, para todas as crianças e adolescentes (RUIZ; FRIAS, 2016, p. 8).

No Brasil essa proposição se instaura a partir da Constituição Federal de 1988, que aborda a questão da criança e do adolescente como prioridade absoluta, 
estabelecendo a garantia de seus direitos como dever da família, da sociedade e do Estado.

É dever da família, da sociedade e do Estado assegurar à criança, ao adolescente e ao jovem, com absoluta prioridade, o direito à vida, à saúde, à alimentação, à educação, ao lazer, à profissionalização, à cultura, à dignidade, ao respeito, à liberdade e à convivência familiar e comunitária, além de colocá-los a salvo de toda forma de negligência, discriminação, exploração, violência, crueldade e opressão. (BRASIL, 1988, art. 227).

A ruptura definitiva, no que se refere ao ordenamento legal com a doutrina da situação irregular, até então admitida pelo Código de Menores (BRASIL, 1979), ocorre com o Estatuto da Criança e do Adolescente -- ECA (BRASIL, 1990), ao reafirmar o texto constitucional.

A criança e o adolescente gozam de todos os direitos fundamentais inerentes à pessoa humana, sem prejuízo da proteção integral de que trata esta Lei, assegurando-se-lhes, por lei ou por outros meios, todas as oportunidades e facilidades, a fim de lhes facultar o desenvolvimento físico, mental, moral, espiritual e social em condições de liberdade e de dignidade (BRASIL, 1990, art. $3^{\circ}$ ).

No reordenamento legal o que se altera é a perspectiva da ação do Estado frente à conduta delituosa do menor de dezoito anos. O Código de Menores de 1979 refletia uma concepção de infância e adolescência "menorizada", que não incorporava a ideia de cidadania.

A partir do ECA, as crianças e adolescentes são considerados sujeitos de direitos, destinatários de políticas públicas. Em seu art. $2^{\circ}$, considera a pessoa até doze anos de idade incompletos como criança, e adolescente aquela entre doze e dezoito anos de idade e, excepcionalmente, a aplicação se dá às pessoas entre dezoito e vinte e um anos de idade, como, por exemplo, nos casos de prolongamento da medida socioeducativa de internação e assistência judicial, até os vinte e um anos. O Estatuto assume, em consonância com a Convenção dos Direitos da Criança, o dispositivo quanto ao entendimento de "criança como todo o ser humano menor de dezoito anos".

No caso do México, a adoção deste modelo se deu em 2005 com a reforma do artigo18 da constituição, a qual ordena a criação em todo o país de um novo sistema integral de justiça penal para adolescentes que deixa para trás o antigo modelo tutelar baseado na doutrina da situação irregular da infância (RUIZ; FRIAS, 2016, p. 8). 
Nessa direção, a atenção aos adolescentes prevê medidas socioeducativas, distinguidas em seu conjunto entre meio aberto e meio fechado, ou seja, as medidas em cumprimento que possibilitam a manutenção de convívio rotineiro em sua comunidade integral ou parcial e as de internação que envolvem a privação de liberdade parcial ou total. No caso do Brasil, são previstas: advertência; obrigação de reparar o dano; prestação de serviços à comunidade; liberdade assistida; inserção em regime de semiliberdade; internação em estabelecimento educacional (BRASIL, 1990).

Por sua vez, as medidas desenvolvidas em meio aberto, pela fundação pesquisada no México, incorporaram novas concepções para acompanhar o desenvolvimento dos adolescentes entendidos e atendidos como sujeito de direitos. Entretanto, para a plena adoção e efetivação dessas concepções, se faz necessário o

[...] replanejamento do compromisso dos sistemas estatais de justiça para adolescentes, que deem lugar para estabelecer programas de atenção multidisciplinares, integrais, éticos, comunitários e de qualidade, que incidem na geração de capacidades e habilidades sociais nos adolescentes e que paralelamente os afastem de reincidir em condutas delitivas. (RUIZ; FRIAS, 2016, p. 21-22).

Portanto, tal mudança de perspectiva em curso, concebendo a criança e o adolescente como sujeito de direitos, subsidia a concepção de programas, com novas abordagens metodológicas, capazes de abordar a multidimensionalidade que caracteriza a adolescência e que situa o adolescente em conflito com a lei. Assim, os esforços das equipes multidisciplinares terão em mente que a "[...] liberdade assistida ou qualquer outra medida é antes de tudo uma estratégia interdisciplinar na qual se desenha um plano de trabalho para acompanhar o desenvolvimento pessoal, familiar e comunitário do adolescente e sua família (CASTELLANOS GARCIA et al., 2011, p. 18)”.

A mudança de paradigma impulsionada a partir dos dispositivos da CDC (ONU, 1989) situa o adolescente em conflito com a lei no contexto da proteção integral e, desta forma, em condições de receber medidas socioeducativas e não meramente punitivas, tendentes a interferir em seu processo de desenvolvimento, com vistas a fortalecer uma melhor compreensão da realidade e exercício de sua cidadania, exigindo 
para sua efetividade não somente a ação do Estado, mas o envolvimento das famílias e da rede comunitária.

\section{A rede de significados nas representações sociais sobre adolescência}

As representações sociais extraídas das narrativas dos educadores de uma instituição que atende adolescentes em conflito com a lei, no cumprimento de medidas socioeducativas não privativas de liberdade, ou seja, em meio aberto, estão ancoradas em duas direções em contradição, constituindo as redes de significados acerca dos adolescentes. "A definição da representação social como rede de significados construídos em torno do núcleo imagético, trazida por Moscovici em 1961” (SOUSA et al., 2014, p. 48).

A primeira dessas direções está constituída por narrativas cuja rede de significações obstrui os propósitos do trabalho socioeducativo, em conformidade com as políticas para a infância contemporânea. Em tais narrativas, podemos identificar a permanência de representações sobre a adolescência como problema, delinquência, nas quais preponderam discursos enredados em linhas de representações sociais com aporte no modelo da situação irregular da adolescência.

Das representações sociais, nessa primeira direção, que obstruem, extraímos três núcleos de significados: 1 . Núcleos de significados que descrevem a adolescência como problema; 2. Núcleo de significados que descrevem os condicionantes contextuais na produção dos desvios da adolescência; 3. Núcleo de significados que descrevem o modelo de abordagem com os adolescentes.

No primeiro núcleo estão relacionadas narrativas cujos significados descrevem os adolescentes como problemas, relacionando-os à criminalidade, como violentos, delinquentes, destacam também o imediatismo da adolescência, gerando crises, e, ainda, 
a adolescência como etapa muito vulnerável e os adolescentes em conflito com a lei como causas perdidas.

Penso que, em geral, os adultos consideram os jovens parte do problema, e não a solução, não acho que sejam apenas um problema nesse momento. (EDUCADOR 15)

Acredito que o que fazemos aqui é importante, indispensável, infelizmente é tão pouco visto. $\mathrm{Na}$ perceção social, há pouca consciência desses problemas, de uma perspetiva humanista. Que se está (no programa) do lado, como dizê-lo, da criminalidade, prepondera o medo, (que vê o adolescente) como criminoso. (EDUCADOR 3)

As crianças e adolescentes, creio que estão mais vulneráveis agora, nesse contexto social. (EDUCADOR 6)

Eu acho que a sociedade está minimizando muito os direitos das crianças e adolescentes, acho que estamos mais focados em prestar atenção a nós mesmos, a adultos e idosos, ou a grupos menores, mas a jovens como um grande grupo, sinto que os estamos deixando à deriva. A pirâmide populacional já está inclinada para pessoas com mais de trinta anos. (EDUCADOR 8)

Os jovens se preocupam apenas com suas necessidades imediatas, recreação e comida. Vejo como um déficit colocar-se a correr riscos, aventurando-se em compromissos coletivos. (EDUCADOR 13)

Posso perceber, crianças e jovens com muito menos controle de impulso, em um ambiente muito mais violento e com respostas muito mais violentas. (EDUCADOR 15)

Essas representações estereotipadas sobre adolescência funcionam como forma de invisibilizar as dificuldades e demandas da adolescência, sobretudo em contextos fortemente marcados pela pobreza infantil. Assim, "[...] ser jovem de um bairro ou setor marginal, equivale a ser 'perigoso', violento, drogado, ladrão e até 'assassino' em potencial ou concretamente”. (CASTELLANOS GARCIA et al., 2011, p. 31).

No segundo núcleo estão relacionadas narrativas que situam condicionantes contextuais que atuam na produção dos desvios da adolescência abrangendo: a violência estrutural, injustiça, desigualdade econômica e social, falta de políticas e programas de prevenção, minimização dos direitos de crianças e adolescentes, desigualdade de condições e de oportunidades, pressão social do consumismo.

Mas sinto que, porque os recursos dados a essas áreas são muito pequenos, muito pequenos; Por isso, se já é difícil trabalhar nessa área, com poucos recursos, ainda mais. (EDUCADOR 3)

Em geral, as crianças e os adolescentes, que estão tendo que viver neste mundo de hoje, têm condições muito mais difíceis do que as que tivemos [...] (EDUCADOR 6) 
Falta de programas, falta de políticas, para realmente entrar nessa abordagem de prevenção. (EDUCADOR 10)

[...] Infelizmente, devido à questão financeira. [...], há muita desigualdade no nível econômico. [...] (EDUCADOR 10)

Acredito que nem em todos os contextos, nem todos têm as mesmas oportunidades que os outros, há jovens que têm a facilidade de estar em espaços que geram recursos para suas vidas; contar com o apoio de pessoas ou instituições. Também existem crianças e jovens que não têm essa oportunidade e é por isso que também se colocam em situações ou comportamentos que não os favorecem em suas vidas. (EDUCADOR 12)

Vejo muita divisão, muitos contrastes entre crianças e adolescentes no meu país, contrastes que são marcados principalmente pela economia. (EDUCADOR 13)

Eu acredito que neste país as desigualdades sociais também têm um impacto para que uma pessoa possa exercer plenamente seus direitos. E aqui geralmente trabalhamos com garotos que vêm de contextos desfavorecidos. Isso limita o acesso, até os pais estão cientes disso. Então eu creio que é uma situação em um nível geral, existem desigualdades sociais e econômicas de acesso à cultura, à educação. (EDUCADOR 16)

O caso da violência é uma questão super normalizada, nem mesmo é possível perceber os efeitos da violência nas pessoas que a sofrem. (EDUCADOR 16)

No terceiro núcleo estão relacionadas narrativas que situam e descrevem o modelo de abordagem com os adolescentes, abrangendo: falta de habilidades parentais com destaque para: falta de proteção no âmbito das famílias (foi o aspecto mais destacado pelos participantes), a violência como recurso disciplinador, normalização da violência nos cotidianos, invisibilidade das crianças e adolescentes que estão sós, à própria sorte, desvalorização da educação, da formação por parte dos pais e ou responsáveis. E, por outro lado, as crianças e adolescentes estão também sujeitos ao excesso de informações sem sentido, apresentam indiferença diante da vida e têm tido perda de valores, em especial, o respeito.

[...] por haver realmente muitos pais que não sabem o que seus filhos estão fazendo fora de casa, eles se limitam apenas ao trabalho e não se preocupam em ver o que faz falta aos seus filhos. [...] eles acreditam que com uma bronca, um grito ou um golpe o garoto entenderá e não é verdade. $\mathrm{E}$ existem meninos que realmente trazem tantas coisas, que não confiam nos pais o suficiente. (EDUCADOR 1)

Muitas questões que os meninos veem são a normalização da violência, tráfico e violências, tudo isso se vê como graves. Eles gostam de ter armas, vender drogas, o poder, o estado que the dá dinheiro. (EDUCADOR 9) 
A falta de responsabilidade, falta de atenção por parte dos pais. Ou, às vezes, os pais precisam trabalhar até altas horas da noite. Não existe uma consciência real dos pais, de como é a educação, o que é ser pai. (EDUCADOR 10)

[...] falta de educação, concepção real da importância do estudo, importância da formação [...] (EDUCADOR 10)

Parece-me que há excesso de informação e que ela perde seu significado. (EDUCADOR 11)

As crianças e adolescentes estão sozinhos. Todas as obrigações que existem nos excedem e paramos de ver algo tão essencial quanto o relacionamento. (EDUCADOR 11)

Vejo muita indiferença diante da vida ao seu redor. Os jovens se preocupam apenas com suas necessidades imediatas, recreação e comida. Vejo como um déficit colocar-se a correr riscos, aventurando-se em compromissos coletivos. Vejo que há pouco respeito pela própria vida, pela natureza. (EDUCADOR 13)

Penso que, como sociedade estamos muito mal, os valores foram perdidos, o respeito foi perdido, as raízes foram perdidas, tradições foram perdidas. Todos os tipos de educação foram perdidos. (EDUCADOR 14)

As representações dos profissionais que atuam na socioeducação indicam uma dialética da travessia paradigmática nas representações sociais, entre as narrativas ancoradas na visão da situação irregular do menor para concepção das crianças, adolescentes e jovens como sujeito de direitos.

Penso que ainda estamos em transição para menores de idade, como objeto de proteção em direção a um modelo em que as crianças são verdadeiramente sujeito de direito, ainda permanece no nível do governo, no nível das famílias [...]. Mas realmente não os capacitamos como sujeitos de direito. Um pouco do nosso trabalho é esse, sim há que cuidá-los, mas também há essa outra parte. (EDUCADOR 16)

As narrativas situam também a importância da responsabilidade coletiva na construção de novas representações, superando redes de significados construídas ao longo da história.

Mas é uma questão histórica, simplesmente não percebemos que a juventude é uma possibilidade e não um problema. (EDUCADOR 15)

De certa forma, como adultos, temos um grande compromisso com eles, acho que às vezes existem muitas maneiras que lhes podem ser violentas ou gerar algum dano. (EDUCADOR 12)

Tal desafio está posto nas concepções e nos encaminhamentos dos programas socioeducativos, mas constituem demandas importantes, que se configuram desde a 
CDC (ONU, 1989), reafirmados pelo ECA (BRASIL, 1990), abrangendo a formação e atuação dos profissionais da educação e da socioeducação. Essa demanda se apresenta tanto para a formação inicial quanto para a formação continuada.

Acredito que minha geração, a maioria das pessoas que trabalham, precisamos nos atualizar, não apenas na ação, mas na teoria, porque os adolescentes vão muito mais rápido do que nós. Renovação do conhecimento. (EDUCADOR 8)

A segunda direção das representações dos profissionais da socioeducação está constituída por narrativas cuja rede de significações tem ancoragem nos referenciais da atenção prioritária e integral à criança e ao adolescente como sujeito de direitos em desenvolvimento. As narrativas que identificam representações sobre a adolescência e sobre o trabalho socioeducativo, compreendendo o adolescente em conflito com a lei como sujeito de direitos, podem ser agrupadas em três núcleos de significados. Em conformidade com as políticas para a infância contemporânea, de tais narrativas extraímos três núcleos de significados: 1. Núcleos de significados que descrevem a adolescência como sujeito de direitos; 2. Núcleo de significados que descrevem abordagem multidisciplinar com os adolescentes como sujeito de direitos, com ênfase no trabalho coletivo; 3. Núcleo de significados que descrevem os propósitos e resultados advindos do modelo de abordagem com os adolescentes como sujeitos de direitos.

No primeiro núcleo dessa perspectiva estão relacionadas narrativas cujos significados descrevem os adolescentes em processo de mudança, peculiar aos sujeitos em desenvolvimento, e sinalizam também a postura consciente e protagônica dos jovens.

A adolescência é um processo de mudança, esse processo de mudança, eles ou os adolescentes, podem ter essa possibilidade de dizer, está canhão (difícil), mas eu tenho esses recursos. E isso implica ter consciência, não? A vida é sempre um processo de mudança. O problema não é mudar, mas como eu experimento a mudança. Como me posiciono com essa mudança. (EDUCADOR 7)

Mas eu também vejo muitos jovens muito mais comprometidos, em fazer parte da mudança e colaborar nessa transformação. (EDUCADOR 15) 
As narrativas em torno desse primeiro núcleo sinalizam a transição do modelo de crianças como objetos de proteção para um modelo no qual as crianças e adolescentes sejam sujeitos de direito, capazes de tomar consciência sobre si, seus contextos individuais e coletivos. Assim, as crianças e adolescentes podem ser fortalecidos, assumindo maior compromisso e responsabilidade nos processos.

Nessa direção estão as narrativas do segundo núcleo da perspectiva, que aborda o trabalho coletivo em equipe de apoio multidisciplinar com crianças e adolescentes concebidos como sujeito de direitos. A ênfase da abordagem está no diálogo, na apresentação do apoio emocional, educativo e jurídico com olhar individualizado para a situação de cada sujeito, se estendendo também para o apoio à família, com participação obrigatória dos pais ou responsáveis legais.

E ao chegar a esse lugar, na verdade, gera confiança nos meninos para poder conversar com os pais, porque se trabalha com a família e se trabalha com o menino para construir confiança entre ambos. Acontece que quando falo com os meninos, sempre consulto também os pais [...]. Eu gosto de trabalhar com adolescentes. (EDUCADOR 1)

Mas parece-me que é um bom caminho, adoro o que se pode contribuir, me apaixonei pelo sistema de como funciona aqui, é algo que eu gosto [...] trabalhar com esses adolescentes, trabalhar com a equipe. (EDUCADOR 2)

[...] eu sinto que o voto de confiança, daquilo que essas instituições conseguem impactar nos adolescentes, terá impacto no futuro dos adultos. (EDUCADOR 8)

Temos que ver sempre adiante, ensiná-los e mais do que ensiná-los, crescer junto com as crianças e os jovens. Enfatizar que apesar das adversidades, como seres humanos, você terá a capacidade de avançar assertivamente. (EDUCADOR 17)

O trabalho coletivo cria vínculos de confiança para o diálogo, com fortalecimento do adolescente com ferramentas de apoio multidisciplinar no trabalho de reinserção social com a força da ajuda de todos, da equipe atuando de modo coordenado com os adolescentes e suas famílias.

O programa promove estratégias para o adolescente se desenvolver e avançar de forma assertiva, com acompanhamento emocional, afetivo com aporte teórico-metodológico de múltiplas linguagens e perspectivas para entender os adolescentes em conflito com a lei. Entre as estratégias da abordagem em 
desenvolvimento estão: trabalho em diálogo individualizado; trabalho sobre situações de risco; assessoria acadêmica nos planos de estudo individuais; acompanhamento do adolescente e da família de modo integrado; aplicação de linguagens artísticas e corporais; empatia e respeito às histórias de vida dos adolescentes.

O terceiro núcleo aglutina narrativas que reportam a relação entre propósitos e resultados alcançados pelos adolescentes e suas famílias, advindos do conjunto de esforços coordenados pela equipe multidisciplinar de educadores e na socioeducação. A constituição de recursos garantidores de direitos promove fortalecimento de habilidades para a vida com superação de consumo de drogas, retomada de estudo e trabalho. Esse fortalecimento viabiliza a ressignificação do projeto de vida, a reinserção do adolescente.

Vemos meninos que retornam, que continuam sem receber novas medidas, que continuam sem consumir drogas, que encontram emprego, que voltam depois de ir para a universidade, por exemplo, com bolsa de estudos, e então, esses exemplos me parecem os mais positivos e temos outro número de exemplos negativos. (EDUCADOR 2)

Estamos muito comprometidos com a reintegração dos adolescentes, porque acreditamos que eles estão vivendo um momento, como para recuperar um projeto de vida que os afastará da dor. (EDUCADOR 4)

[...] então acho que o trabalho que fazemos com eles, com aqueles que estão aqui, precisa acolhêlos, fortalecê-los, porque não podemos mudar o contexto, a realidade de fora. Então devemos fortalecê-los de dentro para que eles tenham as ferramentas, tanto crianças como adolescentes, para enfrentar o mundo tão difícil que agora lhes está tocando. (EDUCADOR 6)

Essa é uma realidade como uma desvantagem, de não ver, pois você percebe como é realmente um adolescente em nível social, mas do ponto de vista, do meu ideal, isso me dá a possibilidade de conseguir certas ações. (EDUCADOR 7)

Temos que ver sempre adiante, ensiná-los e mais do que ensiná-los, crescer junto com as crianças e os jovens. Enfatizar que apesar das adversidades, como seres humanos, você terá a capacidade de avançar assertivamente. (EDUCADOR 17)

Os educadores destacam a postura de mobilização empática, a alteridade, buscando aprender e crescer juntos, educadores e educandos, acreditando na importância do trabalho que realizam com os adolescentes.

Sinto muita sorte, orgulho, amo trabalhar com adolescentes e com a família, porque isso também me permitiu ser cada vez ou tentar ser um ser humano cada vez melhor, e sei que se eu tenho 
problemas, eu sei que existem pessoas que têm mais problemas do que eu. Mas juntos podemos nos ajudar. (EDUCADOR 17)

Essa postura presente nas representações estabelece aporte teórico-metodológico capaz de fazer significativa diferença entre a reincidência e a reintegração dos adolescentes.

A reincidência supõe voltar a cometer infração, assinalamos, com referência em Castellanos Garcia et al. (2011, p. 261-262):

[...] a infração é um sintoma e não a causa da conduta, a reincidência em sentido amplo nos remete à permanência ou agravamento das causas, se trata das situações de risco, e por consequência nos remete necessariamente a efetividade das instituições e seus processos de intervenção [...].

A reinserção, ou melhor, a reintegração social, por sua vez, supõe a reincorporação na coletividade, no exercício de direitos e deveres individuais e coletivos. Entretanto, cabe um alerta. "No caso das condutas infratoras, a reintegração não pode ser entendida sem se considerar as contradições próprias do sistema social que exclui parte de seus membros" (CASTELLANOS GARCIA et al., 2011, p. 266).

Nesse sentido, “[...] a reintegração, também deve ser vista desde o binômio exclusão-inclusão social [...]" (CASTELLANOS GARCIA et al., 2011, p. 267), pois a exclusão abrange todas as pessoas “[...] que não podem adaptar-se às mudanças econômicas e sociais, e que se situam ou são situadas, por ele, fora do sistema produtivo e do desenvolvimento" (p. 267).

A exclusão nesse sentido é um fenômeno social caracterizado pelas dificuldades de integração na sociedade de um número crescente de pessoas à esfera dos bens econômicos (mercado de trabalho, nível de vida e consumo), das instituições (escolares, sanitárias, culturais), das representações e valores correntes (drogas, condutas antissociais) e da aplicação dos direitos humanos. (CASTELLANOS GARCIA et al., 2011, p. 267)

Nessa direção, a reintegração social bem-sucedida supõe inclusão que contribui e, ao mesmo tempo, requer uma transformação significativa nas condições sociais e econômicas.

Parece-me que, no final, o objetivo último de Reintegrar tinha que desaparecer porque, supunha-se que estamos fazendo uma mudança significativa. [...] a verdade é que estamos dizendo que é muito 
significativo para os meninos, os adolescentes, o que leva a promover na sociedade, na sua família, na sua comunidade. (EDUCADOR 2)

A transformação para inclusão social está dirigida “[...] ao acesso e gozo dos bens materiais e existenciais que podem garantir o livre desenvolvimento e a diminuição da vulnerabilidade; a promoção de formas de participação e informação." (CASTELLANOS GARCIA et al., 2011, p. 267).

Trata-se de um enorme desafio, com uma travessia ainda longa, em direção à garantia de direitos e superação da fragilidade de direitos que configuram a multidimensionalidade da pobreza infantil.

\section{Considerações finais}

Refletir sobre as narrativas dos educadores e suas representações sociais sobre adolescentes e adolescentes em conflito com a lei nos permite compreender aspectos relevantes sobre as práticas socioeducativas e os entraves que ainda dificultam a proteção integral aos adolescentes, conforme preconiza a legislação. Ao longo das narrativas, observa-se a condição dialética, manifestada pela dualidade de direções, no que se refere a sua efetivação.

As representações referendadas na teoria da situação irregular, identificadas em uma primeira direção, "justificam" a violação dos direitos das crianças e adolescentes pobres, demarcando-os como outsiders, marginais, identificando o adolescente como problema, relacionando-o à criminalidade, como violento, objeto de intervenção social e não como sujeito de direitos. A percepção da etapa da adolescência é enfatizada pelo imediatismo, vulnerabilidades e condicionantes estruturais. Associa-se o binômio pobreza/delinquência, e considera-se o adolescente em conflito com a lei como causa perdida.

Tais narrativas estão associadas à concepção intervencionista e atuam como uma forma de transferência da responsabilidade política e social coletiva para com as 
crianças, adolescentes e jovens e de justificativa para medidas repressivas duras e, até mesmo, para silenciar o extermínio dos jovens pobres, gerando um clima de hostilidade, medo e indiferença, alimentado em narrativas estereotipadas e preconceituosas.

As representações sociais percebidas nas narrativas e que seguem uma segunda direção, evidenciam a visão de adolescência em processo de mudança, na qual a ênfase está nas condições dos sujeitos nesse processo, vistos como protagônicos na constituição de suas identidades, capazes de tomar consciência de si, seus contextos individuais e coletivos e em condição de assunção de seus compromissos e responsabilidades em seus processos.

Nesse sentido, a prática institucional é desenvolvida na perspectiva multidisciplinar, enfatiza o trabalho coletivo e centra a ação na escuta, no diálogo, na apresentação do apoio emocional, educativo e jurídico com olhar individualizado para a situação de cada sujeito, se estendendo também para o apoio à família, com participação obrigatória dos pais ou responsáveis legais. Assim, o que se busca é a constituição de recursos garantidores de direitos que promovam o fortalecimento e a ressignificação do projeto de vida de adolescentes, que temporariamente se encontram em cumprimento de medida socioeducativa, em função de prática delitiva.

As medidas socioeducativas, antes de serem sancionatórias, são de cunho pedagógico. Portanto, quando o enfoque da medida não está no aspecto educativo, comunicativo, no envolvimento das famílias, retrocede-se no desenvolvimento da garantia de direitos e no processo de construção e fortalecimento de identidade dos sujeitos.

As representações sociais sobre adolescência, nas quais ainda persistem narrativas da "situação irregular", ampliam sobremaneira as demandas das práticas socioeducativas, que, além do trabalho multidisciplinar, desafiam a desconstrução de tais referências na perspectiva da garantia dos direitos da infância.

O acompanhamento, auxílio e orientação, a promoção social dos adolescentes e de sua família envolvidas no processo, bem como a inserção no sistema educacional e qualificação profissional, potencializa a construção e/ou fortalecimento de projetos 
de vida, capazes de produzir a ruptura com a prática delitiva e a adequada integração social. Entretanto, a verdadeira inclusão social ocorre com implementação de políticas públicas que garantam melhores condições de vida aos destinatários da socioeducação, que sobrevivem em grande parte distantes de padrões mínimos que lhes permitam usufruir uma cidadania plena.

Nesse contexto, precisa-se dar maior visibilidade às condições de vida e atendimento desses sujeitos, uma vez que a fragilidade das garantias de direitos intensifica a exclusão social, aprofunda as desigualdades de oportunidades e impacta na identificação desses sujeitos quanto ao seu lugar na sociedade.

As práticas de educação e socioeducação destinadas a esse segmento da infância requerem atenção e estratégias de prevenção de danos consistentes com a garantia dos direitos das crianças e adolescentes, com política integrada e abordagem multissetorial.

Essa infância está circunscrita às condições excludentes da pobreza infantil, considerada em sua natureza multidimensional e não meramente material. E, nas margens fundas nas quais estão os adolescentes pobres, as rupturas são ainda mais abissais, no contexto atual da pandemia que, por si só, acarreta medos e incertezas sobre a própria existência humana.

\section{Referências}

ALVES-MAZZOTTI, A. J. Histórias de vida de professores, formação e representações sociais: uma proposta de articulação. Revista de Educação Pública, Cuiabá, v. 24, n. 55, p. $81-101,2015$.

BASTOS, A.; VEIGA, F. (org.). A análise o bem-estar das crianças e jovens e os direitos da criança. Vila Nova de Famalicão: Edições Húmus, 2016. p. 27-34.

BASTOS, A. et al. Um olhar sobre a pobreza Infantil: análise das condições de vida das crianças. Coimbra: Edições Almedina, 2008.

BASTOS, A. et al. Números com esperança: abordagem estatística da Pobreza Infantil em Portugal: da análise às propostas de actuação. Coimbra: Edições Almedina, 2011. 
BRAGANÇA, I. F. S.; LIMA, R. P. Narrativas de vida de instrutores da educação profissional como possibilidade de estudos no campo das representações sociais. Revista Brasileira de Estudos Pedagógicos, Brasília, v. 97, n. 246, p. 290-304, maio/ago. 2016.

BRASIL. Lei no 6.697, de 10 de outubro de 1979. Institui o Código de Menores. Diário Oficial da União, seção 1, p. 14945, 11 de outubro de 1979. Disponível em: <http://www.planalto.gov.br/ccivil_03/leis/1970-1979/L6697.htm>. Acesso em: 22 maio 2020.

BRASIL. Constituição da República Federativa do Brasil. 1988. Disponível em: http://www.planalto.gov.br/ccivil_03/constituicao/constituicao.htm Acesso em: 22 maio 2020.

BRASIL. Estatuto da Criança $e$ do Adolescente. 1990. Disponível em: http://www.planalto.gov.br/ccivil_03/leis/18069.htm. Acesso em: 22 maio 2020.

CASTELLANOS GARCIA, F. et al. La reintegración de adolescentes en conflicto con la ley. Ciudad de México: Reintegra, 2011.

CASTELLANOS GARCIA, F. et al. Las medidas no privativas de la libertad en la justicia para adolescentes. Ciudad de México: Reintegra; Unicef, 2012. 27 p.

EYNG, A. M. (org.). Infâncias e violências: garantia de direitos no cotidiano de crianças e adolescentes: contribuições de programas desenvolvidos na órbita estatal e da sociedade civil no âmbito internacional. Curitiba: PUCPRESS, 2019.

FERNANDES, N. Infância, Direitos e Participação. Representações, Práticas e Poderes. Porto: Afrontamento, 2009.

FUNDO DAS NAÇÕES UNIDAS PARA A INFÂNCIA (Unicef). Situação Mundial da Infância 2016: oportunidades justas para cada criança. 2016. https://www.unicef.org/brazil/pt/SOWC2016_ResumoExecutivo.pdf. Acesso em: 6 ago. 2018.

MOSCOVICI, S. La phycanalyse, son, image et son public, étude sur la représentation sociale de la phychanalyse. Paris: Presses Universitaires de France, 1961.

MOSCOVICI, S. Razón y culturas. Discurso pronunciado por motivo de investidura como Doctor Honoris Causa en la Universidade de Sevilla, Espanha, 1993.

PASSEGGI, M. C. A experiência em formação. Educação, Porto Alegre, v. 34, n. 2, p. 147-156, maio/ago. 2011.

ONU [Organização das Nações Unidas]. Convenção sobre o direito da Criança. Resolução 44/25 da Assembleia Geral das Nações Unidas. Nova York, 1989.

RIBEIRO, L. P.; CARVALHO, C. A. S.; ANTUNES-ROCHA, M. I. Representações sociais em movimento: uma análise de duas pesquisas no âmbito da educação do campo da FaEUFMG. Revista Educaşão e Cultura Contemporânea, v. 14, n. 37, 2017. 
RUIZ, E. Z.; FRIAS, S. G. Sanciones en libertad: manual para la construcción de redes de colaboración para la reintegración social de adolescentes en conficto con la ley. Ciudad de México: Reintegra; UNICEF, 2016.

SARMENTO, M. J. Pobreza infantil: factos, interpretações e desafios políticos. In: SARMENTO, M. J.; VEIGA, F. (orgs.). Pobreza das crianças: realidades, desafios, propostas. Vila Nova de Famalicão: Húmus, 2010. p. 179-191.

SOUSA, C. P. et al. Angela Arruda e as representações sociais: estudos selecionados. Curitiba: Champagnat; São Paulo: Fundação Carlos Chagas, 2014.

TEIBE, É. N. H.; ANDRADE, D. B. S. F. Práticas de cuidado à criança no contexto hospitalar. Psicologia e Saber Social, v. 6, n. 1, p. 87-100, 2017.

RECEBIDO: 30/05/2020

APROVADO: 28/07/2020

RECEIVED: 05/30/2020

APPROVED: 07/28/2020

RECIBIDO: $30 / 05 / 2020$

APROBADO: $28 / 07 / 2020$ 